and other findings support their conclusions concerning the immunological importance of their results. We have also learned of two other men, at another brewery, each of whom developed severe dyspnoea requiring hospital treatment after handling Clortol. The men had been exposed to the material for one and 15 years before developing symptoms.

To prevent this sensitisation occurring we recommend that the following precautions be taken. Handling the material in dry, powder form in open conditions is inadvisable. Once sensitised, handlers and bystanders will not be able to work in the same part of the building as that in which chloramine is handled, since potentially severe asthma attacks may follow minimal exposure. Unless dispensed as a liquid and used in such a way that formation of aerosols is avoided, dry particles must be heavy enough not to become readily airborne. If the chloramine is in a fine powder form the containers should be airtight and opened only under water or in a glove box, or else with the operator fully protected, ideally by wearing an air-fed hood or suit or a properly fitting, appropriate filter-type mask, preferably pressurised. Laboratory workers should avoid spillages and open containers of the dry powder only in enclosed conditions or a fume cupboard. The principles of controlling health hazards from pulmonary sensitisers are similar to those recommended for enzyme powders. ${ }^{15}$

We thank Drs P G Cronk, S S Kerry, J A McCraith, and Alan Neville; Sisters J Billington, V Cadwallader, and J Spencer; and the patients and brewery managements for their co-operation.
APPENDIX - Some preparations of chloramine (chloramine- $T$ )

Acti-chlore

Aktiven

Anexol

Berkendyl

Chloralone

Chloramine

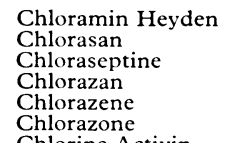

Chlorosol
Clorina
Clorosan
Euclorina
Gansil
Gyneclorina
Halamid

Heliogen

Kloramin
Mannolite

Mianine

Tampules

Tochlorine

Tolamine

\section{References}

${ }^{1}$ Pepys, J, in Clinical Aspects of Immunology. Oxford, Blackwell, 1968.

2 Taylor, H D, and Austin, J H, Fournal of Experimental Medicine, 1918, 27, 635.

${ }^{3}$ Serin, F, Acta Pharmacologica et Toxicologica, 1949, 5, suppl No 1.

${ }^{4}$ Dangerous Properties of Industrial Materials, ed N I Sax. New York, Reinhold, 1968.

5 Gleason, N M, et al, Clinical Toxicology of Commercial Products. Baltimore, Williams and Wilkins, 1969.

${ }^{6}$ Kabe, J, Fapanese Fournal of Allergy, 1971, 20, 444

The Extra Pharmacopoeia, ed A Wade, 27th edn. London, Martindale, 1977.

${ }^{8}$ Flindt, M L H, Lancet, 1969, 1, 1177.

9 Newhouse, M L, et al, Lancet, 1970, 1, 689

10 Hunter, W, British Medical Bulletin, 1974, 30, 18.

${ }^{11}$ Humphrey, J H, and White, R G, in Immunology for Students of Medicine. Oxford, Blackwell, 1970.

12 Flindt, M L H, Lancet, 1978, 1, 430.

${ }^{13}$ Gell, P G H, and Coombs, R R A, in Clinical Aspects of Immunology. Oxford, Blackwell, 1968.

${ }^{14}$ Feinberg, S M, and Watrous, R M, fournal of Allergy, 1945, 16, No 5, 209.

15 Flindt, M L H, Process Biochemistry, 1978, 13, No 8, 3.

(Accepted 26 May 1979)

\title{
Long-term parenteral exposure to mercury in patients with hypogammaglobulinaemia
}

\author{
M R HAENEY, G F CARTER, W B YEOMAN, R A THOMPSON
}

British Medical fournal, 1979, 2, 12-14

\section{Summary and conclusions}

Patients with hypogammaglobulinaemia commonly receive regular long-term replacement therapy with a concentrate of pooled normal human immunoglobulin G (IgG) containing an organic mercury compound (thiomersal) as a preservative. In 26 such patients the total estimated mercury dosage received ranged from 4 to $734 \mathrm{mg}$ (mean $157 \mathrm{mg}$ ) over treatment periods of six months to 17 years (mean 6.5 years). Nineteen patients $(73 \%)$ had raised urine mercury concentrations, but no correlation was found between urine mercury and the age of the patient, the IgG dose, or the duration of treatment.

Urine mercury concentrations are often used to control

\footnotetext{
Regional Immunology Laboratory, East Birmingham Hospital, Birmingham B9 5ST

M R HAENEY, MRCP, MRCPATH, senior registrar R A THOMPSON, FRCP, MRCPATH, director

Regional Toxicology Laboratory, Dudley Road Hospital, Birmingham B18 7QH

G F CARTER, chief medical laboratory scientific officer W B YEOMAN, FRIC, FRCPATH, director
}

exposure and evaluate risks in exposed subjects. Hence most patients with hypogammaglobulinaemia are theoretically at risk from mercury exposure, although no clinica: evidence of toxicity is yet apparent.

\section{Introduction}

Hypogammaglobulinaemia is characterised by very low serum immunoglobulin concentrations resulting in recurrent infections with pyogenic organisms. The condition may be secondary either to protein loss from the renal or gastrointestinal tract or to depressed synthesis-for example, in reticuloendothelial malignancy - or it may arise as a primary condition of unknown aetiology. The usual treatment is regular administration of a concentrate of normal human immunoglobulin $\mathrm{G}$ (IgG) derived from pooled plasma (Blood Products Laboratory, National Blood Transfusion Service, Elstree, Herts) and containing about $150 \mathrm{mg} \mathrm{IgG} \mathrm{per} \mathrm{ml:} \mathrm{thiomersal} \mathrm{(sodium} \mathrm{ethylmercurithiosalicy-}$ late) is added at a concentration of $0 \cdot 1 \mathrm{~g} / 1$ as a preservative. Most patients are satisfactorily maintained on a weekly intramuscular dose of 25 or $50 \mathrm{mg} / \mathrm{kg}$ body weight, ${ }^{1}$ and some patients have been given regular injections for over 20 years.

A potential long-term hazard of such treatment arises from the use of a mercurial compound as a preservative. In view of both the known toxicity of mercury and the relation between the duration of exposure and its effect on man we have examined the consequences of prolonged parenteral administration of a mercury compound in patients with hypogammaglobulinaemia. 


\section{Patients and methods}

We studied 26 patients who fulfilled Medical Research Council criteria for hypogammaglobulinaemia ${ }^{1} ; 16$ were male and 10 female, and their ages ranged from 4 to 67 years (mean 21 years). They had been receiving replacement therapy for six months to 17 years (mean 6.5 years), their weekly IgG dosage ranging from $0.45 \mathrm{~g}$ to $3.0 \mathrm{~g}$ (mean $1.2 \mathrm{~g}$ ). The immunodeficiency was considered to be primary in 23 cases and secondary to reticuloendothelial malignancy in three. The primary immunodeficiency syndromes were further classified into common variable immunodeficiency (16 cases) and infantile sex-linked hypogammaglobulinaemia (seven cases).

Urine total mercury concentrations were determined in all patients. Urine samples $(20 \mathrm{ml})$ were collected the day before the weekly injection and passed into polycarbonate containers with screw tops. This material was used in preference to polystyrene, polypropylene, or glass to prevent adsorption of mercury on to the walls. ${ }^{2}$ Triplicate samples were obtained from 17 patients and duplicate samples from the remaining nine. The mercury concentrations in 15 different batches of IgG concentrate were also determined in triplicate; six replicates of two batches were obtained.

Urine mercury was estimated by the "cold-vapour" technique, ${ }^{3}$ a double beam atomic absorption spectrophotometer (Instrumentation Laboratories IL 353) being used. The lower limit of detection is $10 \mu \mathrm{g} / \mathrm{l}$. The upper limit of normal is taken as $30 \mu \mathrm{g} / 1$ (95\% distribution of population). Accuracy of the method is better than $95 \%$ at concentrations above $50 \mu \mathrm{g} / \mathrm{l}$, and precision is thought to be $\pm 10 \%$ at $10-50 \mathrm{~kg} / 1$, improving to $\pm 5 \%$ above $50 \mu \mathrm{g} / \mathrm{l}$. Experience in industry suggests that clinical symptoms are not overt at concentrations below $150 \mu \mathrm{g} / \mathrm{l}$.

\section{Results}

Fig 1 shows the mercury concentrations in different batches of immunoglobulin in relation to the age of the batch, the expiry date normally being four years after manufacture. There was a significant

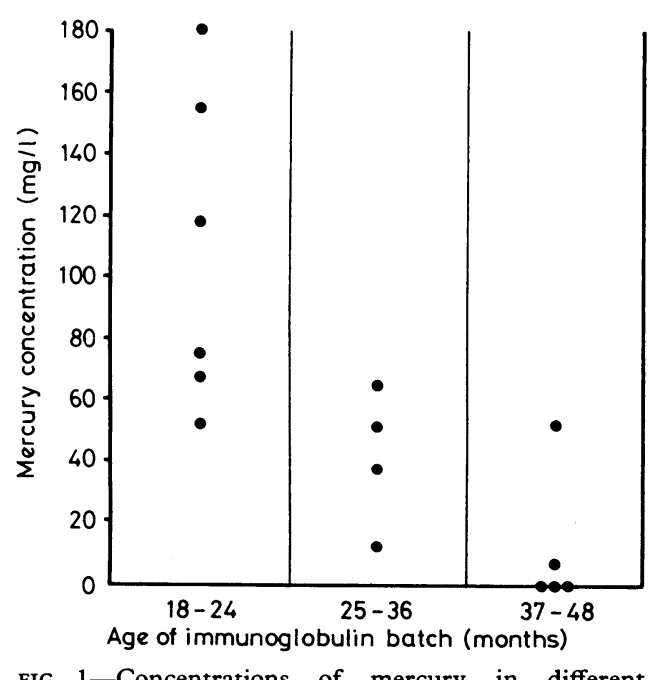

immunoglobulin batches in relation to age of batch

decline in the mercury content with age of the batch $(r=-0.735$; $P<0.01$ ), being particularly pronounced beyond 24 months after manufacture. In three batches nearing their expiry date (42-48 months) no mercury was detected. A considerable variation in the mercury concentration in ampoules from the same batch was also found; in the two batches from which six replicates were obtained the variation was $29 \%$ and $62 \%$.

Table I gives the estimated total thiomersal dose received by each patient since beginning treatment. Thiomersal exposure ranged from 8 to $1482 \mathrm{mg}$ (mean $317 \mathrm{mg}$ ), equivalent to mercury dosages of $4-734 \mathrm{mg}$ (mean $157 \mathrm{mg}$ ).

Table II shows the urine mercury concentrations in the 26 patients. Concentrations exceeded $30 \mu \mathrm{g} / 1$ in 19 patients $(73 \%), 45 \mu \mathrm{g} / 1$ in 12 $(46 \%)$, and $75 \mu \mathrm{g} / \mathrm{l}$ in $3(12 \%)$. Urine mercury concentrations showed no significant correlation with the weekly maintenance dose of immunoglobulin (and hence thiomersal), the duration of immunoglobulin exposure, or the age of the patient at initial exposure.

In three patients urine mercury concentrations were determined both before starting treatment and after six months of replacement therapy (fig 2); in all cases the concentration increased during treatment.

TABLE I-Thiomersal exposure in 26 patients with hypogammaglobulinaemia

\begin{tabular}{|c|c|c|c|c|c|}
\hline $\begin{array}{l}\text { Case } \\
\text { No }\end{array}$ & $\begin{array}{l}\text { Years on } \\
\text { treatment }\end{array}$ & $\begin{array}{l}\text { IgG dose } \\
\text { (mg/week) }\end{array}$ & $\begin{array}{c}\text { Thiomersal } \\
\text { dose } \\
\text { (mg/week) }\end{array}$ & $\begin{array}{l}\text { Estimated } \\
\text { total } \\
\text { thiomersal } \\
\text { received } \\
(\mathrm{mg})\end{array}$ & $\begin{array}{c}\text { Estimated } \\
\text { total } \\
\text { mercury } \\
\text { received } \\
\text { (mg) }\end{array}$ \\
\hline $\begin{array}{r}1 \\
2 \\
3 \\
4 \\
5 \\
6 \\
7 \\
8 \\
9 \\
10 \\
11 \\
12 \\
13 \\
14 \\
15 \\
16 \\
17 \\
18 \\
19 \\
20 \\
21 \\
22 \\
23 \\
24 \\
25 \\
26\end{array}$ & $\begin{array}{r}15 \\
17 \\
16 \\
14 \\
5 \\
7 \\
11 \\
7 \\
9 \\
10 \\
9 \\
6 \\
5.5 \\
2.5 \\
4 \\
6 \\
4 \\
6 \\
5 \\
4 \\
2.5 \\
4 \\
1 \\
0.5 \\
0.5 \\
0.5\end{array}$ & $\begin{array}{r}2850 \\
1650 \\
1650 \\
1725 \\
3000 \\
2100 \\
975 \\
1350 \\
900 \\
750 \\
750 \\
1050 \\
900 \\
1950 \\
1125 \\
750 \\
900 \\
600 \\
525 \\
600 \\
750 \\
450 \\
1125 \\
1500 \\
1350 \\
900\end{array}$ & 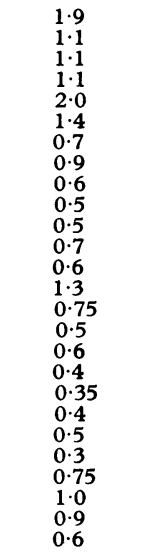 & $\begin{array}{r}1482 \\
972 \\
915 \\
837 \\
520 \\
510 \\
372 \\
328 \\
280 \\
260 \\
234 \\
218 \\
171 \\
169 \\
156 \\
156 \\
125 \\
125 \\
91 \\
83 \\
65 \\
62 \\
39 \\
26 \\
23 \\
8\end{array}$ & $\begin{array}{r}734 \\
482 \\
453 \\
415 \\
258 \\
253 \\
184 \\
163 \\
139 \\
129 \\
116 \\
108 \\
85 \\
84 \\
77 \\
77 \\
62 \\
62 \\
45 \\
41 \\
32 \\
31 \\
19 \\
13 \\
11 \\
4\end{array}$ \\
\hline $\begin{array}{l}\text { Range } \\
\text { Mean }\end{array}$ & $\begin{array}{c}0.5-17 \cdot 0 \\
6.5\end{array}$ & $\begin{array}{c}450-3000 \\
1240\end{array}$ & $\begin{array}{c}0 \cdot 3-2 \cdot 0 \\
0 \cdot 8\end{array}$ & $\begin{array}{c}8-1482 \\
317\end{array}$ & $\begin{array}{c}4-734 \\
157\end{array}$ \\
\hline
\end{tabular}

TABLE II-Distribution of urine mercury concentrations in the 26 patients

$\begin{array}{llllllllll}\text { Urine mercury }(\mu \mathrm{g} / \mathrm{l}) & \ldots & \ldots & \ldots & 0-15 & 16-30 & 31-45 & 46-60 & \geqslant 61 \\ \text { No of patients } & . & \ldots & \ldots & \ldots & 3 & 4 & 7 & 9 & 3\end{array}$

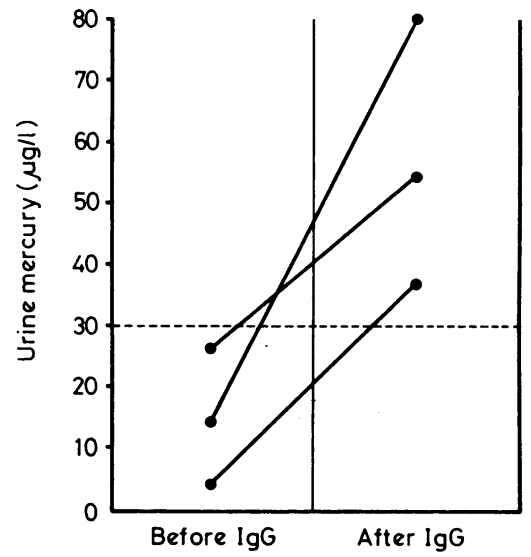

FIG 2-Urine mercury concentrations in three patients before treatment with IgG and after six months of replacement therapy. Upper limit of normal taken as $30 \mu \mathrm{g} / 1$.

\section{Discussion}

Because of the need to avoid iatrogenic hazards we have investigated the risk of mercury toxicity in patients receiving long-term replacement IgG therapy for hypogammaglobulinaemia. The IgG is distributed in rubber-capped glass bottles with a shelf life of four years. We have shown that not only is there considerable variation in the amount of thiomersal present in each container but that the mercury content is inversely correlated with the age of the batch; this disappearance of 
mercury is probably due to adsorption on to the glass walls and rubber stopper. ${ }^{2}$

Everyone is exposed to small amounts of environmental mercury through food, water, and air. The upper limit for the urine mercury concentration in "normal" people is generally accepted as below $20 \mu \mathrm{g} / 1,{ }^{4}$ although considerable geographical variation exists. Thus even when $30 \mu \mathrm{g} / \mathrm{l}$ was taken as the upper limit for urine mercury concentrations 19 of our 26 patients had raised values. No correlation was found, however, between the urine mercury concentration and the age of the patient, the IgG dose, or the duration of treatment.

Few data are available on the quantitative evaluation of long-term exposure to organic mercury compounds. In one case of acute organic mercury poisoning from thiomersal a calculated total mercury dose of $280 \mathrm{mg}(0.14 \mathrm{mg} / \mathrm{kg} /$ day $)$ was administered over three months as a plasma preservative to a 13-year-old boy with protein-losing enteropathy: the urine mercury concentration was $5.3 \mathrm{mg} / 1 .{ }^{5}$ In contrast, four other patients transfused with plasma containing $0.01 \%$ thiomersal as preservative were excreting 50-600 $\mu \mathrm{g}$ mercury daily after consequent mercury doses of 3-210 mg but developed no acute symptoms or signs. ${ }^{5}$ In experiments thiomersal was given intravenously to 21 patients in doses up to $250 \mathrm{mg}$ mercury and the subjects observed from one to 62 days after administration. ${ }^{\circ}$ "Nephritis" was reported in one case, and thrombophlebitis in another; no other symptoms were observed.

In our series the total estimated mercury dosage in patients with hypogammaglobulinaemia ranged from 4 to $734 \mathrm{mg}$ (mean $157 \mathrm{mg}$ ), whereas the intensity of exposure was low in view of the prolonged treatment periods, ranging from six months to 17 years (mean 6.5 years). None of our 26 patients had overt clinical evidence of mercury toxicity. ${ }^{7}$ Neurological or intestinal symptoms that were present in our patients usually predated treatment and were attributed to the well-recognised complications of antibody deficiency. Three other patients (not included here) had uneventful pregnancies and gave birth to healthy children while receiving regular replacement therapy.

The urine mercury concentration may be considered to be an unreliable index of individual exposure to mercury, especially to alkyl mercury compounds, but urinary concentrations are often used to control exposure and evaluate risks in exposed subjects. Hence most patients with hypogammaglobulinaemia are theoretically at risk from mercury exposure, and although no clinical evidence of toxicity is yet apparent, physicians responsible for such patients must be alert to the need for continued, long-term, detailed clinical examination to detect any subtle disturbances ${ }^{7}$ that may occur.

\section{References}

${ }^{1}$ Medical Research Council, Hypogammaglobulinaemia in the United Kingdom. London, HMSO, 1971.

2 Wiener, S, fournal of Pharmacy and Pharmacology, 1955, 7, 118.

${ }^{3}$ Lindstet, G, Analyst, 1970, 95, 264.

4 World Health Organisation, WHO Occupational Health, 1966, 66, 39.

5 Suzuki, T, fournal of the fapanese Medical Association, 1969, 61, 1051.

6 Powell, H M, and Jamieson, W A, American fournal of Hygiene, 1931, 13, 269.

${ }^{7}$ Skerfving, S, and Vostal, J, in Mercury in the Environment: An Epidemiological and Toxicological Appraisal, ed L Friberg and J Vostal, p 93. Cleveland, C R C Press Inc, 1972.

(Accepted 21 May 1979)

\title{
Relation between medicines sweetened with sucrose and dental disease
}

\author{
I F ROBERTS, G J ROBERTS
}

British Medical fournal, 1979, 2, 14-16

\section{Summary and conclusions}

The teeth of 44 children aged under 6 years who had been taking syrup medicines regularly for at least six months were compared with those of a control group of 47 children of similar ages. Dental disease was assessed by measuring dental caries, dental plaque, and gingivitis. The children who were receiving sucrose-based medicines had significantly more carious teeth and gingivitis.

It is concluded that sucrose-based medicines continuously administered to children cause dental caries and gingivitis. Liquid medicines for children should be either unsweetened or sweetened with non-cariogenic substances.

Department of Child Health, St George's Hospital, London SW17 0QT I F ROBERTS, MB, MRCP, senior registrar

Department of Children's Dentistry and Orthodontics, Royal Dental Hospital, London WC2H 7LJ

G J ROBERTS, BDS, PHD, senior lecturer in children's dentistry

\section{Introduction}

Children with chronic diseases often require long-term medication. To improve palatability and perhaps patient compliance pharmaceutical companies supply many liquid medicines sweetened with sucrose. Sufficient evidence has now accrued from dental studies to support the relation between bacterial dental plaque, sucrose (or other fermentable carbohydrate), and the principal oral diseases of dental caries, ${ }^{1}$ gingivitis, and periodontal disease. ${ }^{2}$ We designed the present study to test the hypothesis, formulated from clinical impressions, that children taking liquid medicine containing sucrose on a long-term basis suffer more dental caries, plaque accumulation, and gingivitis than others.

\section{Patients and methods}

A paediatrician (IR) selected children for the investigation from hospital outpatients. They were aged between 9 months and 6 years, had chronic medical disorders, and had been attending hospital outpatient clinics regularly for at least six months. The study group comprised 44 children who had been prescribed liquid medicines on a daily basis throughout the preceding six months or longer. In all cases the nature of the drug and the frequency of prescription were verified by examining the hospital records. The sweetening agent was confirmed to be sucrose. A control group was formed of 47 children of similar ages who either received no medication or took medication in tablet form. 